\title{
Histopathologic Findings of Eyes Enucleated After Treatment with Chemosurgery for Retinoblastoma
}

\author{
Carolyn P. Graeber ${ }^{1,2}$, Y. Pierre Gobin ${ }^{1,3}$, Brian P. Marr ${ }^{1}$, Ira J. Dunkel ${ }^{1}$, Scott E. Brodie ${ }^{1,4}$, \\ Norbert Bornfeld ${ }^{5}$, Devron H. Char ${ }^{6}$, Robert Folberg ${ }^{7}$, Saskia M. Imhof ${ }^{8}$, Amy Y. Lin ${ }^{9}$, \\ Jesse L. Berry ${ }^{1,10}$, Saleh Al Mesfer ${ }^{11}$, Annette C. Moll ${ }^{12}$ and David H. Abramson ${ }^{*}, 1$ \\ ${ }^{I}$ Memorial Sloan-Kettering Cancer Center, New York, NY, USA \\ ${ }^{2}$ New York University School of Medicine/Manhattan Eye, Ear \& Throat Hospital, New York, NY, USA \\ ${ }^{3}$ New York-Presbyterian Hospital, Weill Medical College of Cornell University, New York, NY, USA \\ ${ }^{4}$ Mount Sinai Hospital, New York, NY, USA \\ ${ }^{5}$ University of Duisburg-Essen, Essen, Germany \\ ${ }^{6}$ Stanford University, Stanford, CA, USA \\ ${ }^{7}$ Oakland University William Beaumont School of Medicine, Rochester, MI, USA \\ ${ }^{8}$ University Medical Center, Utrecht, The Netherlands \\ ${ }^{9}$ University of Illinois at Chicago, Chicago, IL, USA \\ ${ }^{10}$ Doheny Eye Institute, Los Angeles County Medical Center, Los Angeles, CA, USA \\ ${ }^{11}$ King Khaled Eye Specialist Hospital, Riyadh, Kingdom of Saudi Arabia \\ ${ }^{12}$ VU University Medical Center, Amsterdam, The Netherlands
}

\begin{abstract}
Introduction: Intra-arterial chemotherapy (chemosurgery) for the treatment of retinoblastoma has been performed more than 1600 times (more than 1400 times in Japan and 200 times in New York) over the past 20 years. Despite this treatment's success some eyes cannot be saved and require enucleation. Here we report the histopathologic findings of the remaining intraocular tumor of eyes that were enucleated following treatment that included chemosurgery in New York City.

Materials and Methodology: Independent histopathologic review of the enucleated eyes was correlated with the clinical findings that prompted enucleation.

Results: Between May 1, 2006 and April 30, 2009, 56 eyes received chemosurgery at our institution, and 10 of these were enucleated subsequently. All were Reese Ellsworth Group 5 at enucleation. Of the 21 eyes that were treated with chemosurgery as the primary treatment, $1(5 \%)$ was enucleated subsequently; its histopathology revealed residual nonnecrotic, non-calcified tumor. Of the 34 eyes treated with chemosurgery after other treatments, $9(24 \%)$ were enucleated, and 5 of these eyes contained non-calcified, non-necrotic tumor. None was enucleated for complications of chemosurgery. All patients were alive and free of metastatic disease as of September 2009.

Conclusions: A significant number of eyes with advanced intraocular retinoblastoma avoided enucleation as a result of chemosurgery. The rate of eyes that were enucleated was higher when chemosurgery was the secondary rather than the primary treatment. Of the eight eyes enucleated for progressive disease six had non-necrotic, non-calcified tumor cells.
\end{abstract}

Keywords: Retinoblastoma, histopathology, chemosurgery.

\section{INTRODUCTION}

Retinoblastoma may be treated successfully by combinations of enucleation, external beam radiation (EBR), systemic chemotherapy, periocular chemotherapy, and local treatments such as laser, cryotherapy, and brachytherapy.

*Address correspondence to this author at the Memorial Sloan-Kettering Cancer Center, 1233 York Ave, Rm 311, New York, NY 10065, USA; Tel: 212-639-7232; Fax: 212-734-2553; E-mail: abramsod@mskcc.org
Due to the success of these methods, treatment improvements have focused on maintaining the eye, reducing toxicities of treatments, and maximizing visual outcomes. Although the concept of infusing chemotherapy into the arterial blood supply of the eye via the carotid artery is not new [1,2], improvements in interventional radiology techniques now permit the administration of high concentrations of chemotherapeutic drugs directly to the eye via the ophthalmic artery [3], thereby limiting the systemic and intracranial toxicity and increasing drug delivery to the 
target end organ. Japanese investigators have performed and described their experiences with more than 1400 infusions of selective intra-carotid arterial chemotherapy [3-6]. Previously, we described a technique for super-selective drug delivery, further improving the specificity of this technique by using a microcatheter to infuse chemotherapy into the ophthalmic artery (chemosurgery) [7]; we have since treated more than 70 eyes with more than 200 infusions.

There is a paucity of literature published about the enucleated eyes that have been treated by chemosurgery because relatively few eyes treated with this protocol are enucleated. Only one case report has been published describing an eye that was enucleated after extensive treatment, including conventional chemotherapy, intraophthalmic artery and intravitreous injection of melphalan, focal laser, and vitrectomy with additional periorbital melphalan [8]. The report, however, did not comment on the histopathologic findings of the remaining tumor in the enucleated eye. We therefore now report the histopathologic findings of the 10 eyes that were treated in New York and subsequently enucleated through the end of April 2009.

\section{MATERIALS AND METHODOLOGY}

Institutional review board approval was obtained for the retrospective review of 10 charts of patients with retinoblastoma whose tumors were treated with chemosurgery at this institution and who required enucleation after their treatment. The clinical courses of these patients, including their treatment regimens prior to referral and the reasons for referral and enucleation were reviewed. Pathologic findings were reviewed by a pathologist (RF) who was masked to clinical information. Any retinoblastoma tissue identified histologically was classified as necrotic, calcified, or nonnecrotic and non-calcified. The histopathologic findings were then compared with the clinical findings that prompted enucleation as documented in the written chart and by fundus photography. Fisher's exact test was used to compare the number of enucleations in the eyes treated with primary chemosurgery versus those treated previously with other treatment modalities.

\section{RESULTS}

As of April 30, 2009, 56 eyes had received chemosurgery at our institution, of which 10 had been enucleated (see Table 1 for a case summary and Fig. (1) for examples of the fundus photographs prior to enucleation). Of those 10 eyes, 6 were Reese Ellsworth Group 5B, 2 were Group 5A, and 2 were $3 \mathrm{~A}$ at initial presentation. 9 were Reese Ellsworth Group 5B and 1 was Group 5A at the time of enucleation. Four of the patients were female, and 8 had a history of bilateral disease.

Of the 22 eyes that were treated with chemosurgery as the primary treatment, only 1 was enucleated for tumor progression and histopathologic review revealed residual non-necrotic, non-calcified cells. Of the 34 eyes treated with chemosurgery after other treatments, 9 were enucleated-5 for tumor progression, 2 for insufficient regression, 1 for persistent retinal detachment, and 1 for secondary glaucoma from rubeosis iridis with a painful eye. Seven of these 9 patients had been recommended for enucleation and received chemosurgery as salvage therapy--5 received EBR after systemic chemoreduction therapy failed to eradicate the tumor burden, 1 received EBR as primary treatment, and 1 failed systemic chemoreduction and periocular carboplatin. The contralateral eye of three of these patients had been enucleated due to retinoblastoma at presentation to this institution.

The mean time that the eye was maintained after initial treatment with chemosurgery for eyes receiving chemosurgery as salvage treatment was 143 days (range 26 to 343 days). For all eyes, the mean time to enucleation after initial treatment with chemosurgery was 187 days (range 26 days to 484 days). The mean time from diagnosis to enucleation for all patients was 675 days (range 200 to 1548 days). More eyes were enucleated from the group that received chemosurgery as secondary treatment than were enucleated from the group that had received chemosurgery as primary treatment $(\mathrm{P}=.036)$.

On masked histopathologic review, 6 of the 10 enucleated eyes contained persistent, non-necrotic, noncalcified tumor, 2 with residual tumor that was either calcified or necrotic, and 1 with no evidence of tumor (Table 1, Fig. 2). Slides from one patient were not available for histopathologic review. Eight of the 10 eyes had no evidence of invasive disease. Invasion into the choroid, superficial invasion of the sclera, and invasion of the optic nerve past the lamina cribrosa (but not to the resection margin) was identified in only one eye. There was no evidence of retinal arterial occlusion in any of the enucleated specimens.

\section{DISCUSSION}

This report is the first to detail the histopathologic findings of the remaining tumor found in eyes enucleated after treatment with chemosurgery. Of these 9 eyes that were histopathologically reviewed, one had no residual tumor, two had evidence of calcified or necrotic cells, and six had evidence of non-necrotic, non-calcified tumor. Several previous studies have commented on the viability of tumor in histopathologic specimens. From histopathological findings alone, it is not possible to identify which tumor cells might be viable. One could not say with certainty if tumor cells that are neither necrotic nor calcified are viable, but calficified and necrotic cells are not considered to be capable of contributing to tumor growth, invasion, or metastasis. We, therefore, avoided defining viable versus non-viable tumor and commented only on the presence or absence of necrotic or calcified cells.

Of the 6 eyes that were enucleated for progression of disease, 2 of them had either complete tumor regression or calcified tumor on histopathologic review (Fig. 1a and Fig. 1b, respectively). This disconnect between the clinical findings that prompted enucleation and the histopathologic findings raises the question of whether the clinical regression patterns in eyes treated with chemosurgery are different from eyes treated by other treatment modalities. With more experience and with definition of the regression pattern in these patients, it may be possible in the future to monitor these eyes safely without resorting to enucleation. 
Table 1.

\begin{tabular}{|c|c|c|c|c|c|c|c|c|c|c|c|c|c|c|c|c|c|c|c|}
\hline లే & 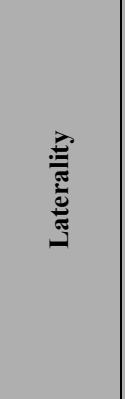 & 兲 & 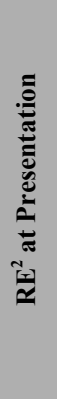 & 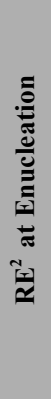 & 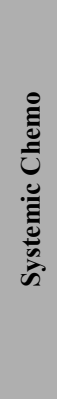 & 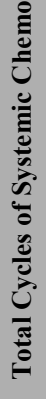 & 善 & $\stackrel{+}{\overbrace{\infty}^{*}}$ & 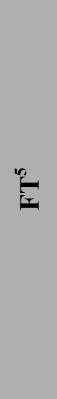 & 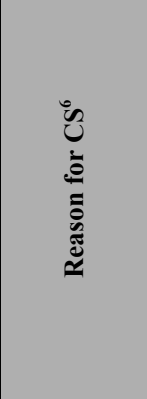 & 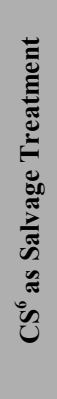 & $\begin{array}{l}\grave{\Xi} \\
\bar{\Xi} \\
\vdots \\
\bar{\Xi}\end{array}$ & 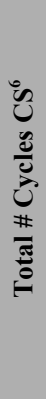 & 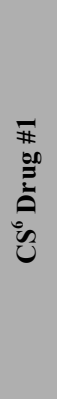 & 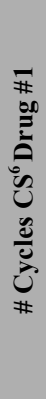 & 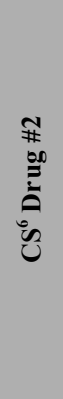 & 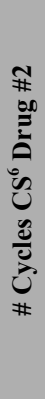 & 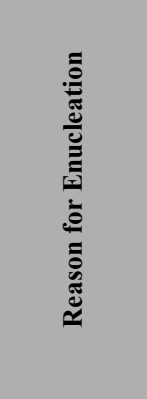 & 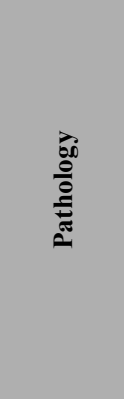 \\
\hline 1 & bilateral & OS & $5 \mathrm{~A}$ & $5 \mathrm{~A}$ & no & -- & yes & -- & no & progression & yes & no & 3 & $\mathrm{M}^{7}$ & 3 & $\mathrm{C}^{8}$ & 3 & progression & $\begin{array}{l}\text { Complete } \\
\text { tumor } \\
\text { regression }\end{array}$ \\
\hline 2 & bilateral & OS & $5 \mathrm{~B}$ & $5 \mathrm{~B}$ & yes & 2 & yes & -- & no & recurrence & yes & no & 1 & $\mathrm{M}^{7}$ & 1 & N/A & -- & $\begin{array}{l}\text { secondary } \\
\text { glaucoma }\end{array}$ & $\begin{array}{l}\text { calcified } \\
\text { cells }\end{array}$ \\
\hline 3 & bilateral & OS & $5 \mathrm{~B}$ & $5 \mathrm{~B}$ & yes & -- & yes & -- & yes & recurrence & yes & no & 3 & $\mathrm{M}^{7}$ & 3 & $\mathrm{~T}^{9}$ & 2 & progression & $\begin{array}{l}\text { calcified } \\
\text { cells }\end{array}$ \\
\hline 4 & bilateral & OD & $5 \mathrm{~B}$ & $5 \mathrm{~B}$ & yes & 15 & yes & $\mathrm{P}$ & yes & $\begin{array}{l}\text { persistent } \\
\text { tumor }\end{array}$ & yes & yes & 5 & $\mathrm{M}^{7}$ & 5 & $\mathrm{~T}^{9}$ & 2 & $\begin{array}{l}\text { insufficient } \\
\text { regression }\end{array}$ & N/A \\
\hline 5 & bilateral & OD & $5 \mathrm{~B}$ & $5 \mathrm{~B}$ & yes & 5 & yes & $\mathrm{P}$ & yes & $\begin{array}{l}\text { persistent } \\
\text { tumor }\end{array}$ & yes & yes & 4 & $\mathrm{M}^{7}$ & 4 & $\mathrm{~T}^{9}$ & 4 & $\mathrm{RD} / \mathrm{VH}$ & $\begin{array}{c}\text { non- } \\
\text { necrotic/ } \\
\text { non- } \\
\text { calcified }\end{array}$ \\
\hline 6 & unilateral & OD & $3 \mathrm{~A}$ & 5B & yes & 4 & no & -- & yes & $\begin{array}{l}\text { inability to } \\
\text { tolerate } \\
\text { systemic } \\
\text { chemo }\end{array}$ & no & no & 3 & $\mathrm{M}^{7}$ & 3 & $\mathrm{~T}^{9}$ & 1 & progression & $\begin{array}{c}\text { non- } \\
\text { necrotic/ } \\
\text { non- } \\
\text { calcified }\end{array}$ \\
\hline 7 & bilateral & OS & $3 \mathrm{~A}$ & $5 \mathrm{~B}$ & no & -- & no & B & yes & recurrence & no & no & 6 & $\mathrm{M}^{7}$ & 6 & $\mathrm{~T}^{9}$ & 3 & $\begin{array}{l}\text { insufficient } \\
\text { regression }\end{array}$ & $\begin{array}{c}\text { non- } \\
\text { necrotic/ } \\
\text { non- } \\
\text { calcified }\end{array}$ \\
\hline 8 & unilateral & OD & $5 \mathrm{~B}$ & $5 \mathrm{~B}$ & no & -- & no & B & yes & $\begin{array}{l}\text { primary } \\
\text { treatment }\end{array}$ & no & no & 3 & $\mathrm{M}^{7}$ & 3 & N/A & -- & progression & $\begin{array}{c}\text { non- } \\
\text { necrotic/ } \\
\text { non- } \\
\text { calcified }\end{array}$ \\
\hline 9 & bilateral & OS & $5 \mathrm{~A}$ & $5 \mathrm{~B}$ & yes & 5 & No & $\mathrm{P}$ & yes & recurrence & yes & no & 3 & $\mathrm{M}^{7}$ & 3 & N/A & -- & progression & $\begin{array}{c}\text { non- } \\
\text { necrotic/ } \\
\text { non- } \\
\text { calcified }\end{array}$ \\
\hline 10 & bilateral & OD & $5 \mathrm{~B}$ & $5 \mathrm{~B}$ & yes & 8 & yes & -- & yes & recurrence & yes & yes & 6 & $\mathrm{M}^{7}$ & 6 & $\mathrm{~T}^{9}$ & 1 & progression & $\begin{array}{c}\text { non- } \\
\text { necrotic/ } \\
\text { non- } \\
\text { calcified }\end{array}$ \\
\hline
\end{tabular}

${ }^{1} \mathrm{EE}=$ eye enucleated ${ }^{2} \mathrm{RE}=$ Reese Ellsworth group ${ }^{3} \mathrm{EBR}=$ External beam radiation ${ }^{4} \mathrm{~B} / \mathrm{P}=$ Brachytherapy/periocular chemotherapy ${ }^{5} \mathrm{FT}=$ focal therapy, including laser and cryotherapy ${ }^{6} \mathrm{CS}=$ chemosurgery ${ }^{7} \mathrm{M}=$ melphalan, ${ }^{8} \mathrm{C}=$ carboplatin, ${ }^{9} \mathrm{~T}=$ topotecan.

It is not the purpose of this study to specifically identify any intraocular toxicity from chemosurgery nor is that possible. Nine of these eyes had received extensive, multimodal treatments to the eye before chemosurgery was attempted as salvage. These nine eyes had different combinations of prior multiagent systemic chemotherapy, EBR, brachytherapy, cryotherapy and laser so it would have been impossible to specifically identify toxicity of the chemosurgery itself. The one eye that was primarily treated with chemosurgery and then enucleated did not show any toxicity in the optic nerve or other ophthalmic structures. In addition, no eye showed evidence of retinal arterial occlusion. None of the eyes in this series was enucleated because of toxicity related to chemosurgery. One eye presented to this institution with a complication of prior treatment-secondary glaucoma from rubeosis iridis. This complication has been associated with EBR [9] and was the primary reason for enucleation.

Chemosurgery was a salvage treatment for 7 of the 9 eyes that were previously treated with other modalities. In two eyes, we detected histopathologic features associated with risk for local and systemic relapse [10-16]. In one of these eyes (Case 8) we detected tumor in the ciliary body with seeding of the anterior chamber (Fig. 2c), and in the other eye (Case 10) we detected choroidal invasion, superficial scleral invasion, and invasion of the optic nerve beyond the lamina cribrosa. 
(a)

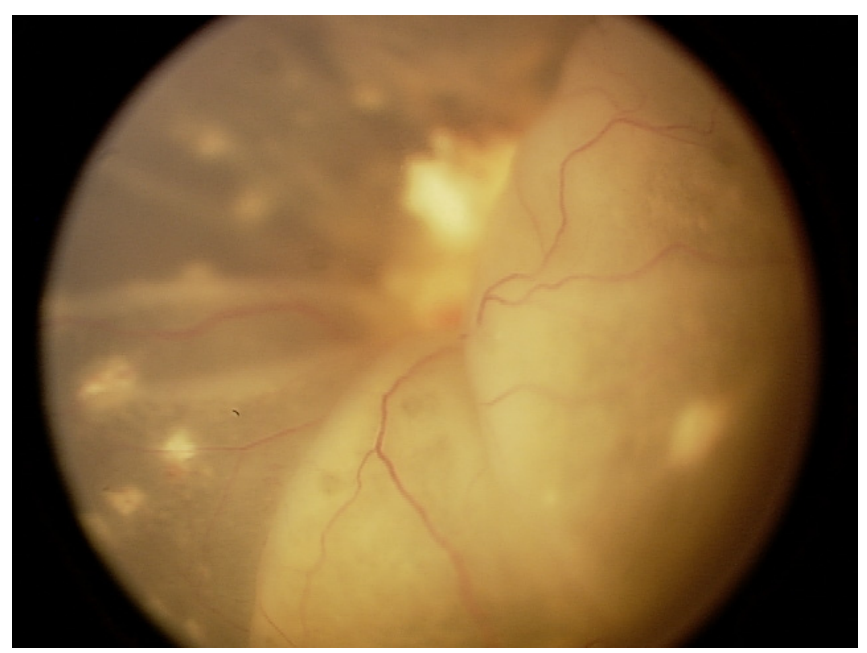

(b)

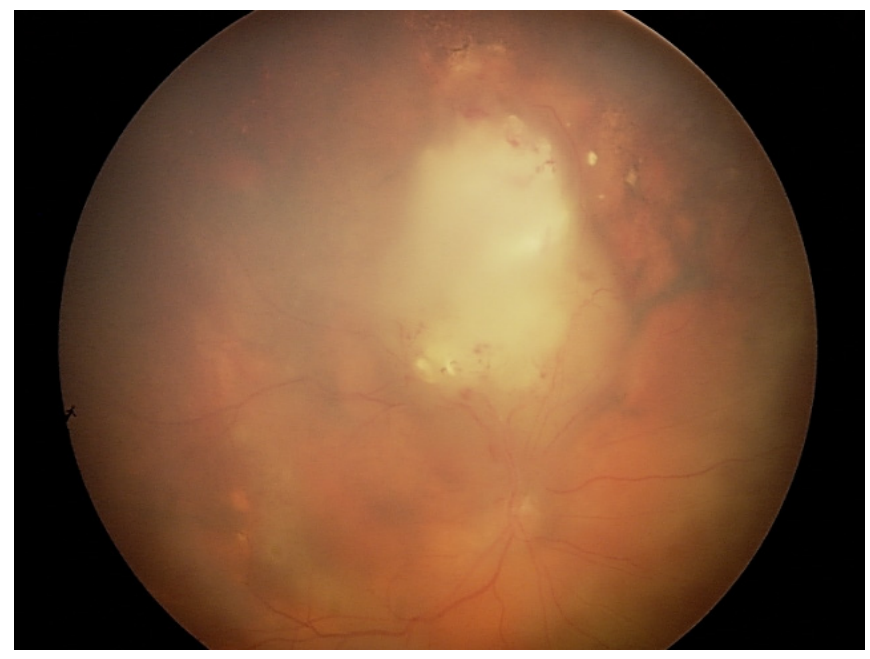

(c)

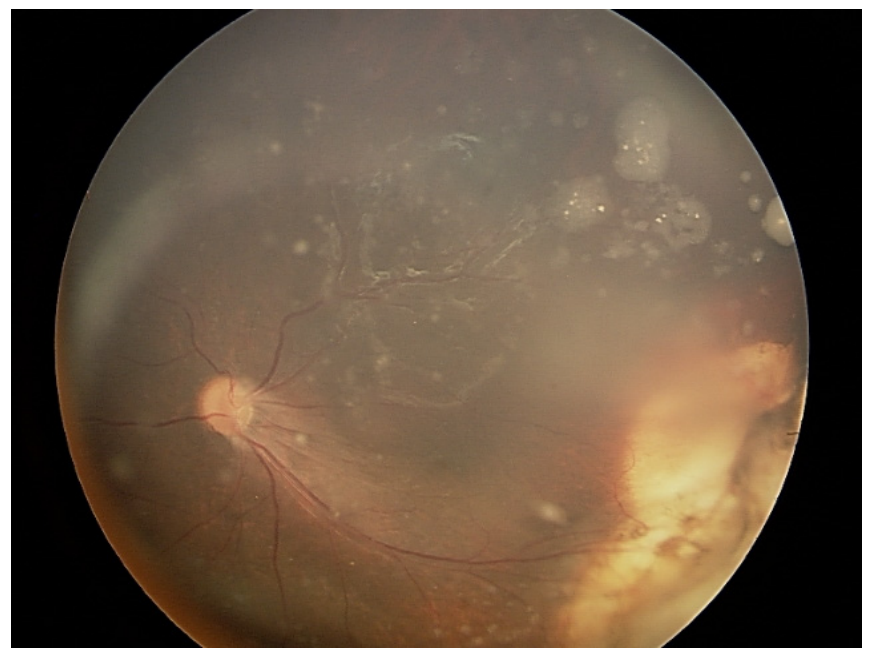

Fig. (1). a) Fundus photograph prior to enucleation of eye with complete tumor regression on histopathologic review (Case 1). (b) Fundus photograph prior to enucleation of eye with necrotic and calcified cells on histopathologic review (Case 3). (c) Fundus photograph prior to enucleation of an eye with non-necrotic, noncalcified cells on histopathologic review (Case 7). (a)

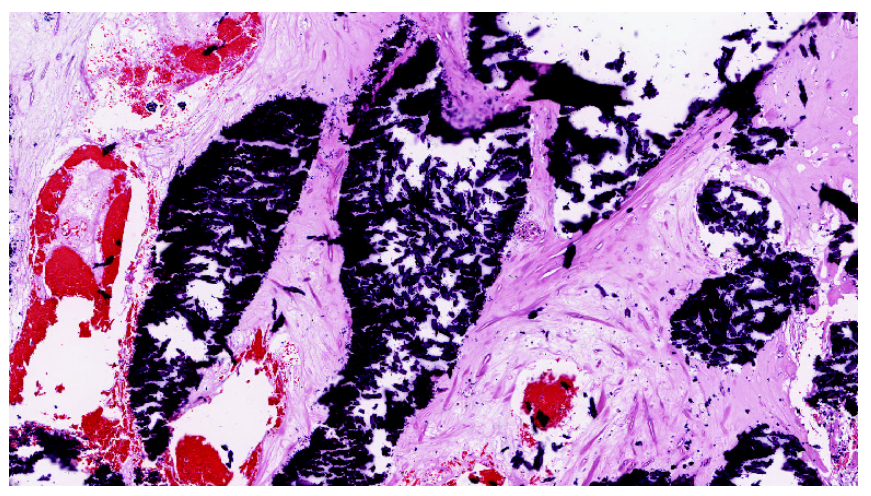

(b)

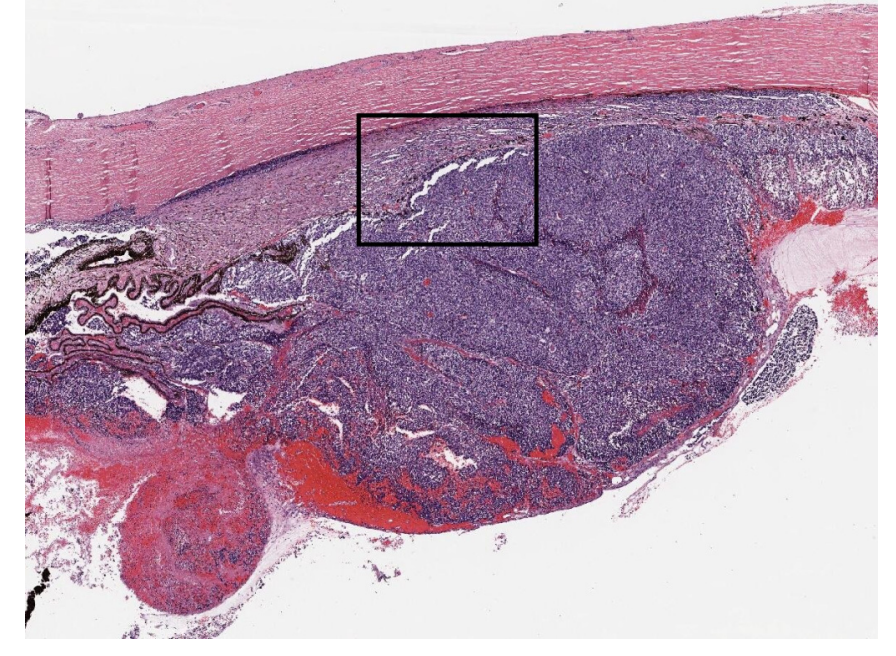

(c)

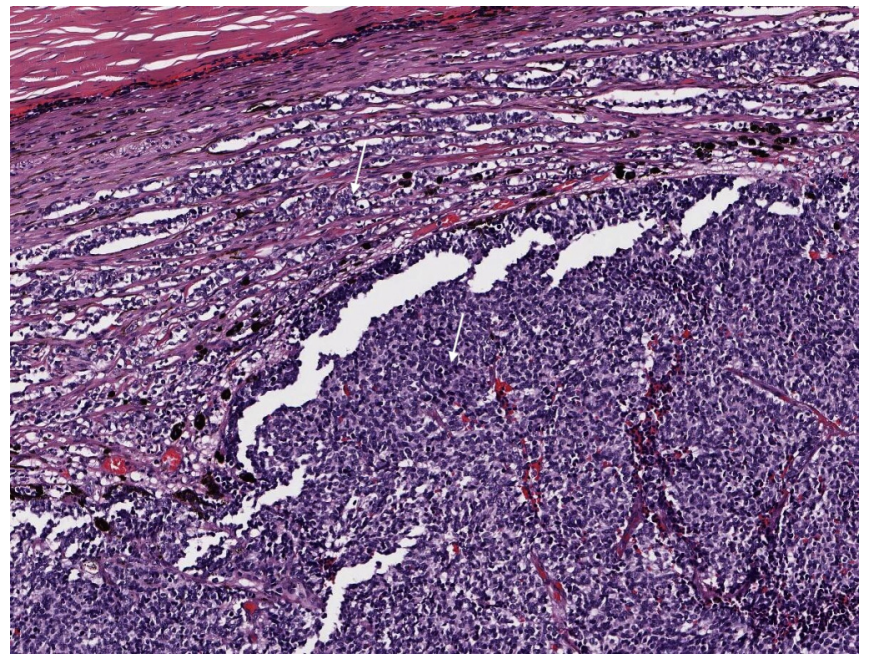

Fig. (2). Hematoxylin and eosin stain of histopathology. (a) Histopathology of patient with calcified cells (Case 2). (b) Histopathology of non-necrotic, non-calcified tumor, low power (Case 8). (c) High power view of boxed area in Figure 2b. Arrows indentify large areas of non-necrotic, non-calcified cells (Case 8).

\section{CONCLUSION}

Overall, chemosurgery has been successful in treating eyes with retinoblastoma and preventing enucleation. Of the 22 patients who had chemosurgery as their primary 
treatment, fewer than $5 \%$ of the eyes were enucleated subsequently. Of the 34 eyes that had failed other treatments, $26 \%$ were enucleated, almost all of which received chemosurgery as salvage treatment. On average, the patients were able to retain the treated eye for over 5.5 additional months. Further investigation is needed to identify histologic evidence of treatment toxicity and to correlate clinical features with histopathological results.

\section{ACKNOWLEDGEMENTS}

Financial support for this project was provided in part by The Fund for Ophthalmic Knowledge and Perry's Promise Fund.

\section{CONFLICTS OF INTEREST}

The authors have no conflicts of interest to report with regard to this manuscript.

\section{REFERENCES}

[1] Reese AB, Hyman GA, Tapley ND, Forrest AW. The treatment of retinoblastoma by $\mathrm{x}$-ray and triethylene melamine. AMA Arch Ophthalmol 1958; 60: 897-906.

[2] Kiribuchi M. Retrograde infusion of anti-cancer drugs to ophthalmic artery for intraocular malignant tumors. Nippon Ganka Gakkai Zasshi 1966; 70: 1829-33.

[3] Yamane T, Kaneko A, Mohri M. The technique of ophthalmic arterial infusion therapy for patients with intraocular retinoblastoma. Int J Clin Oncol 2004; 9: 69-73.

[4] Ueda M, Tanabe J, Inomata M, Kaneko A, Kimura T. Study on conservative treatment of retinoblastoma--effect of intravitreal injection of melphalan on the rabbit retina. Nippon Ganka Gakkai Zasshi 1995; 99: 1230-5.
[5] Kaneko A, Suzuki S. Eye-preservation treatment of retinoblastoma with vitreous seeding. Jpn J Clin Oncol 2003; 33: 601-7.

[6] Suzuki S, Kaneko A. Management of intraocular retinoblastoma and ocular prognosis. Int J Clin Oncol 2004; 9:1-6.

[7] Abramson DH, Dunkel IJ, Brodie SE, Kim JW, Gobin YP. A phase I/II study of direct intraarterial (ophthalmic artery) chemotherapy with melphalan for intraocular retinoblastoma initial results. Ophthalmology 2008;115:1398-404.

[8] Ohshima K, Kaneko T, Takagi S, Kaneko A, Yokouchi Y, Takeuchi S. Clinicopathological investigation of a retinoblastoma eye enucleated after vitreous surgery with melphalan perfusion. Jpn J Ophthalmol 2009; 53:186-8.

[9] Balaguer J, Wilson MW, Billups CA, et al. Predictive factors of invasion in eyes with retinoblastoma enucleated after eye salvage treatments. Pediatr Blood Cancer 2009; 52: 351-6.

[10] Kopelman JE, McLean IW, Rosenberg SH. Multivariate analysis of risk factors for metastasis in retinoblastoma treated by enucleation. Ophthalmology 1987; 94: 371-7.

[11] Magramm I, Abramson DH, Ellsworth RM. Optic nerve involvement in retinoblastoma. Ophthalmology 1989; 96: 217-222.

[12] Khelfaoui F, Validire P, Auperin A, et al. Histopathologic risk factors in retinoblastoma: a retrospective study of 172 patients treated in a single institution. Cancer 1996; 77: 1206-13.

[13] Shields CL, Shields JA, Baez K, Cater JR, De Potter P. Optic nerve invasion of retinoblastoma. Metastatic potential and clinical risk factors. Cancer 1994; 73: 692-8.

[14] Kim JW, Kathpalia V, Dunkel IJ, Wong RK, Riedel E, Abramson $\mathrm{DH}$. Orbital recurrence of retinoblastoma following enucleation. $\mathrm{Br}$ J Ophthalmol 2009; 93: 463-7.

[15] Honavar SG, Singh AD, Shields CL, et al. Postenucleation adjuvant therapy in high-risk retinoblastoma. Arch Ophthalmol 2002; 120: 923-931.

[16] Chantada GL, Dunkel IJ, de Davila MT, Abramson DH. Retinoblastoma patients with high risk ocular pathological features: who needs adjuvant therapy? Br J Ophthalmol 2004; 88: 1069-73. 